\title{
MÚlTIPLOS CENÁRIOS DA CIÊNCIA DA INFORMAÇÃO E DA BIBLIOTECONOMIA BRASILEIRA
}

\author{
MULTIPLE SCENES OF INFORMATION SCIENCE \\ AND THE BRAZILIAN LIBRARIANSHIP \\ MÚLTIPLES ESCENARIOS DE LA CIENCIA DE LA INFORMACIÓN \\ Y LA BIBLIOTECONOMÍA BRASILEÑA
}

Gildenir Carolino Santos ${ }^{1}$

Danielle Thiago Ferreira ${ }^{1}$

${ }^{1}$ Universidade Estadual de Campinas - Sistema de Bibliotecas

\section{Correspondência}

${ }^{1}$ Gildenir Carolino Santos

Universidade Estadual de Campinas - Sistema de Bibliotecas

Campinas, SP

E-mail: $\underline{\text { rdbci@unicamp.br }}$

Submetido em: 24-07-2018

Aceito em: 30-07-2018

Publicado em: 28-08-2018

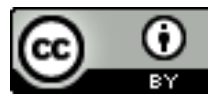

JITA: AA. Library and information science as a field. 
Prezados leitores,

Chegamos à edição do volume 16 , número 3 , correspondente ao período de setembro a dezembro de 2018, sob a temática "Múltiplos cenários da Ciência da Informação e da Biblioteconomia brasileira".

Nessa edição contamos com oito Artigos; um Artigo de pesquisa; um Relato de experiência e uma Resenha.

A relevância da presente temática está em apontar o pensamento dos múltiplos cenários inseridos nas áreas da Ciência da Informação e da Biblioteconomia, especialidade da nossa publicação.

Assim, teremos como subtemas: a produção do conhecimento, governança de dados, das interfaces da leitura documentária no âmbito jurídico, dominação patriarcal presente nas músicas populares discutidas e reescritas na rede social do projeto Arrumando Letras, o olhar para o desenvolvimento sustentável da biblioteca escolar, o documento fotográfico como fator para a geração de conhecimento, considerações sobre os projetos de lei para acessibilidade na web no Brasil, a leitura vista pela análise das Bibliotecas Transcol de Vila Velha por meio da ferramenta Servqual e fecharemos com a verificação dos processos de negócio, a gestão de documentos e os fluxos documentais.

Iniciamos com a seção Artigos, trazendo o primeiro trabalho intitulado "Da prática à produção do conhecimento: bibliotecas e biblioteconomia pré-científica", de autoria de Gabrielle Francinne Tanus, onde a autora traça um resgate histórico com a indissociável relação entre as bibliotecas e a Biblioteconomia conduzida a uma reconstituição da história dessas instituições, começando pelo período mais remoto da Antiguidade e percorrendo para a Idade Média. Para tanto, a autora, realiza um levantamento bibliográfico com autores que abordam a história da biblioteca, particularmente, vinculada aos dois momentos citados anteriormente. Acredita-se que, perscrutar este largo período da história da qual a Biblioteconomia faz parte, possibilitaria uma maior compreensão da mesma, bem como de suas práticas exercidas nas bibliotecas, em especial, na Antiguidade e na Idade Média.

No segundo artigo sobre a "Governança de dados aplicada à ciência da informação: análise de um sistema de dados científicos para a área da saúde", de Priscilla Lüdtke Espíndola, José Francisco Salm Junior, Francisco Rosa e Jordan Paulesky Juliani; que tiveram como objetivo aplicar o "Modelo de ciclo de vida dos dados" e as ferramentas de governança de dados para identificar oportunidades de melhorias para o Sistema de Avaliação Motora, especialmente com relação à qualidade de dados.

$\mathrm{Na}$ sequência trazemos a "Documentação jurídica: interfaces da leitura documentária, linguagem e análise de discurso no tratamento da informação", de Roseli Miranda e Cibele Araújo Camargo Marques dos Santos. As autoras discutem a terminologia e

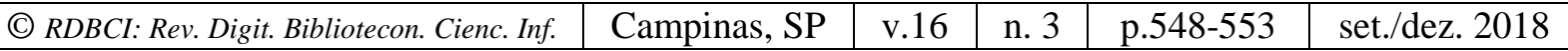


a representação da informação, em função do hermetismo da linguagem e da dificuldade para o profissional bibliotecário na identificação os tipos de discursos jurídicos presentes nos documentos da área.

No quarto artigo sobre "A página arrumando letras como um espaço para a desconstrução da dominação do patriarcado", de Nathália Lima Romeiro, Franciéle Carneiro Garcês da Silva e Anna Cristina Caldeira de Andrada Sobral Brisola. Neste artigo, as autoras se propõem a discutir a dominação patriarcal presente nas músicas populares discutidas e reescritas na página Arrumando Letras na mídia social Facebook, bem como a compreensão dos fenômenos, valores e costumes estudados pela ética, compreendida como a Ciência da moral.

Em "Significados e contextos: leitura e interpretação na Ciência da Informação", Lourival Pinto tem como objetivo refletir sobre a relação entre as leituras, os significados, as interpretações e seus contextos, na ótica da Ciência da Informação. $\mathrm{O}$ artigo traz uma revisão bibliográfica elegendo como temas principais de investigação os significados e seus contextos de significação que podem acontecer nos processos de formação de leitores, facilitando a leitura das pessoas em estruturas significantes mais complexas.

No artigo "Agenda 2030 para o desenvolvimento sustentável: uma leitura de política pública na clave da biblioteca escolar", Claudio Marcondes de Castro Filho apresenta os 17 ODS (Objetivos de Desenvolvimento Sustentável), do programa da ONU que visa transformar o mundo à luz dos parâmetros da biblioteca escolar. A articulação entre o desenvolvimento sustentável e os objetivos da biblioteca escolar permite situar as contribuições no âmbito mais amplo de uma política pública para a educação. Essa articulação gerou alguns pressupostos como: possibilitar o aumento do índice de leitura; a biblioteca escolar como parte do movimento social que busca efetivar as políticas públicas educacionais e culturais; fornecer instrumental necessário para a formação, o desenvolvimento e o aprimoramento das competências do aluno; abrir um espaço de criação e de compartilhamento de experiências.

No sétimo artigo intitulado " $O$ documento fotográfico: um objeto social e de comunicação para a geração de conhecimento" Joana Sousa Rodrigues (Universidade do Porto) afirma que o documento fotográfico constitui um enorme desafio para aquela que é chamada de Era de Informação e que vem aprumada com o avanço tecnológico, nomeadamente a imposição do digital, através de dispositivos de captura de imagem. Assim, o tratamento de informação fotográfica, embora, à primeira vista, espelhe um leque imenso de oportunidades e benefícios ainda padece de um estudo limitado e pouco desenvolvido.

No último artigo da seção Artigos, Wagner Junqueira de Araújo, Ítalo José Bastos Guimarães e Marckson Roberto Ferreira de Sousa no texto sobre os "Cenários prospectivos com base nos projetos de lei para acessibilidade na web no Brasil", os autores abordam a

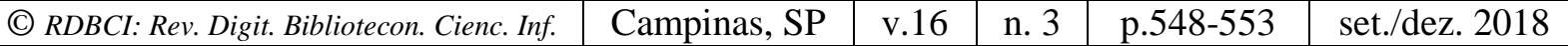


temática da acessibilidade e tem como objetivo elaborar cenários prospectivos para acessibilidade na web com base nos projetos de lei do Senado Federal e da Câmara dos Deputados.

Na seção Artigos de Pesquisa, trazemos o trabalho "Aproveite a sua passagem e viaje pelo mundo da leitura: uma análise das Bibliotecas Transcol de Vila Velha por meio da ferramenta Servqual". Os autores Sandra Maria Souza de Carvalho, Marcelo Calderari Miguel, Ana Claudia Borges Campos refletem que avaliar e reavaliar a qualidade de ajustar as necessidades de sua comunidade são atividades necessárias para qualquer biblioteca. Eles utilizaram nesse relato, a métrica Servqual, para analisar as expectativas e percepção dos associados da Biblioteca Transcol em relação aos serviços ofertados pelos módulos bibliotecários nos terminais de transporte públicos do município de Vila Velha.

Já na seção Relato de Experiência, Livia Marangon Duffles Teixeira e Elisângela Cristina Aganette colaboram com o trabalho intitulado "Os processos de negócio, a gestão de documentos e os fluxos documentais: algumas perspectivas e relações". O presente relato propõe uma discussão entre as temáticas: processos de negócios, gestão de documentos e fluxo documental, tendo como objetivo o dialogar baseado na necessidade de esclarecer a relação dessas temáticas, e explicar a relevância de considerar os documentos como portadores de conteúdo dinâmico, envolvendo seu próprio fluxo de aprovação e ciclo de vida muitas vezes não completamente ligados ao processo em que os mesmos documentos participam.

Na última seção Resenha, Gildenir Carolino Santos, como editor, elaborou a resenha do livro "E-Science e políticas públicas para ciência, tecnologia e inovação no Brasil", de Valdineia Barros Ferreira (UFBA), onde são apresentados os conceitos sobre melhoria e fortalecimento dos laboratórios e grupos de pesquisa como ambientes colaborativos, trazendo questões que dizem respeito as políticas públicas para fomento científico, tecnológico e de inovação e também dos institutos nacionais de ciência e tecnologia, entre outros aspectos.

Assim, terminamos o expediente do ano de 2018 da RDBCI, deixando para nossos leitores desejos de sucesso na finalização deste último semestre de 2018 e início de 2019. Sempre contando com a colaboração e prestigio de vocês, que nos ajudam na construção da revista e que consolidemos novas parcerias e novos estudos a serem publicados em 2019.

Uma boa leitura e até a próxima edição!

Agosto / 2018 


\section{Referências}

ARAÚJO, Wagner Junqueira de; GUIMARÃES, Ítalo José Bastos; SOUSA, Marckson Roberto Ferreira de. Cenários prospectivos com base nos projetos de lei para acessibilidade na web no Brasil. RDBCI: Revista Digital de Biblioteconomia e Ciência da Informação, Campinas, SP, v. 16, n. 3, ago. 2018. ISSN 1678-765X. Disponível em: <https://periodicos.sbu.unicamp.br/ojs/index.php/rdbci/article/view/8652530>. Acesso em: 28 ago. 2018. doi:https://doi.org/10.20396/rdbci.v16i3.8652530.

CARVALHO, Sandra Maria Souza de; MIGUEL, Marcelo Calderari; CAMPOS, Ana Claudia Borges. Aproveite a sua passagem e viaje pelo mundo da leitura: uma análise das Bibliotecas Transcol de Vila Velha por meio da ferramenta Servqual. RDBCI: Revista Digital de Biblioteconomia e Ciência da Informação, Campinas, SP, v. 16, n. 3, jun. 2018. ISSN 1678-765X. Disponível em: <https://periodicos.sbu.unicamp.br/ojs/index.php/rdbci/ article/view/8651239> . Acesso em: 28 ago. 2018. doi:https://doi.org/10.20396/rdbci.v16i3. $\underline{8651239}$.

CASTRO FILHO, Claudio Marcondes de. Agenda 2030 para o desenvolvimento sustentável: uma leitura de política pública na clave da biblioteca escolar. RDBCI: Revista Digital de Biblioteconomia e Ciência da Informação, Campinas, SP, v. 16, n. 3, jun. 2018. ISSN 1678-765X. Disponível em: <https://periodicos.sbu.unicamp.br/ojs/index.php/rdbci/ article/view/8650931 >. Acesso em: 28 ago. 2018. doi:https://doi.org/10.20396/rdbci.v16i3. $\underline{8650931 .}$.

ESPÍNDOLA, Priscilla Lüdtke et al. Governança de dados aplicada à ciência da informação: análise de um sistema de dados científicos para a área da saúde. RDBCI: Revista Digital de Biblioteconomia e Ciência da Informação, Campinas, SP, v. 16, n. 3, ago. 2018. ISSN 1678-765X. Disponível em: <https://periodicos.sbu.unicamp.br/ojs/index.php/rdbci/ article/view/8651080>. Acesso em: 28 ago. 2018. doi:https://doi.org/10.20396/rdbci.v16i3. $\underline{8651080 .}$.

PINTO, Lourival. Significados e contextos: leitura e interpretação na Ciência da Informação. RDBCI: Revista Digital de Biblioteconomia e Ciência da Informação, Campinas, SP, v. 16, n. 3, ago. 2018. ISSN 1678-765X. Disponível em: <https://periodicos.sbu.unicamp.br/ojs/index.php/rdbci/article/view/8652462>. Acesso em: 28 ago. 2018. doi:https://doi.org/10.20396/rdbci.v16i3.8652462.

MIRANDA, Roseli; SANTOS, Cibele Araújo Camargo Marques dos. Documentação jurídica: interfaces da leitura documentária, linguagem e análise de discurso no tratamento da informação. RDBCI: Revista Digital de Biblioteconomia e Ciência da Informação, Campinas, SP, v. 16, n. 3, jun. 2018. ISSN 1678-765X. Disponível em: <https://periodicos.sbu.unicamp.br/ojs/index.php/rdbci/article/view/8650313>. Acesso em: 28 ago. 2018. doi:https://doi.org/10.20396/rdbci.v16i3.8650313. 
RODRIGUES, Joana Sousa. O documento fotográfico: um objeto social e de comunicação para a geração de conhecimento. RDBCI: Revista Digital de Biblioteconomia e Ciência da Informação, Campinas, SP, v. 16, n. 3, ago. 2018. ISSN 1678-765X. Disponível em: 〈https://periodicos.sbu.unicamp.br/ojs/index.php/rdbci/article/view/8651853>. Acesso em: 28 ago. 2018. doi:https://doi.org/10.20396/rdbci.v16i3.8651853.

ROMEIRO, Nathália Lima; SILVA, Franciéle Carneiro Garcês da; BRISOLA, Anna Cristina Caldeira de Andrada Sobral. A página arrumando letras como um espaço para a desconstrução da dominação do patriarcado. RDBCI: Revista Digital de Biblioteconomia e Ciência da Informação, Campinas, SP, v. 16, n. 3, jun. 2018. ISSN 1678-765X. Disponível em: 〈https://periodicos.sbu.unicamp.br/ojs/index.php/rdbci/article/view/8651276>. Acesso em: 28 ago. 2018. doi:https://doi.org/10.20396/rdbci.v16i3.8651276.

SANTOS, Gildenir Carolino. E-Science e políticas públicas brasileiras. RDBCI: Revista Digital de Biblioteconomia e Ciência da Informação, Campinas, SP, v. 16, n. 3, ago. 2018. ISSN 1678-765X. Disponível em: <https://periodicos.sbu.unicamp.br/ojs/index.php/rdbci/ article/view/8653297> . Acesso em: 28 ago. 2018. doi:https://doi.org/10.20396/rdbci. v16i3.8653297.

TANUS, Gabrielle Francinne. Da prática à produção do conhecimento: bibliotecas e biblioteconomia pré-científica.RDBCI: Revista Digital de Biblioteconomia e Ciência da Informação, Campinas, SP, v. 16, n. 3, jun. 2018. ISSN 1678-765X. Disponível em: <https://periodicos.sbu.unicamp.br/ojs/index.php/rdbci/article/view/8651364>. Acesso em: 28 ago. 2018. doi:https://doi.org/10.20396/rdbci.v16i3.8651364.

TEIXEIRA, Livia Marangon Duffles; AGANETTE, Elisângela Cristina. Os processos de negócio, a gestão de documentos e os fluxos documentais: algumas perspectivas e relações. RDBCI: Revista Digital de Biblioteconomia e Ciência da Informação, Campinas, SP, v. 16, n. 3, ago. 2018. ISSN 1678-765X. Disponível em: <https://periodicos.sbu.unicamp.br/ojs/index.php/rdbci/article/view/8651321 >. Acesso em: 28 ago. 2018. doi:https://doi.org/10.20396/rdbci.v16i3.8651321. 